\title{
Manifestations of muscle fatigue in baseball pitchers: a systematic review
}

\author{
Richard Birfer ${ }^{1}$, Michael WL Sonne $^{2}$, Michael WR Holmes ${ }^{\text {Corresp. } 1}$ \\ ${ }^{1}$ Department of Kinesiology, Brock University, St. Catharines, Canada \\ 2 Baseball Development Group, Toronto, Canada \\ Corresponding Author: Michael WR Holmes \\ Email address: mholmes2@brocku.ca
}

Background. Fatigue in baseball pitchers is a process linked to lowered physical and mental performance, injury, and changes in kinematics. Numerous studies have associated fatigue with overuse, high ball velocities, lack of rest time, poor mechanics, and degree of self-satisfaction. The aim of this study was to systematically review the literature to identify a theoretical framework for the relationship between outcomes and the manifestation of fatigue on baseball pitching. The synthesized data may identify areas requiring further research. Methodology. This protocol was registered with PROSPERO (ID: CRD42018114194). SPORTDiscus, Medline, PubMed, Cochrane Database of Systematic Reviews, and Google Scholar were searched, using keywords such as fatigue in pitchers and changes in kinematics (e.g. pitching mechanics, valgus elbow torque), performance (e.g. pitch count, pitch type), and injury (e.g. pain, elbow and shoulder soreness). Three reviewers independently screened the articles, selected relevant literature based on abstract eligibility, and assessed the methods described therein for final inclusion.

Results. 31,860 articles were screened for eligibility and 25 articles were included for the review. The selected articles included epidemiological, longitudinal, experimental, conference papers, and crossover laboratory studies. Evidence extracted from the 25 studies demonstrates a relationship between fatigue in baseball pitching, and three overarching outcomes: changes in kinematics, a decrease in performance, and an increase in injury risk. Conclusions. Findings show that a co-dependence between changes in kinematics and a decrease in performance, which stems from central and peripheral fatigue, is a contributing factor of injury in baseball pitchers. A large percentage of baseball pitchers exhibit pain or soreness in either their elbow or shoulder, or both at some point in a season. Initially, kinematic changes occur that could maintain performance, but may increase joint and tissue loading. Performance decreased with elevated pitch counts and innings thrown, and pitching further into games or the season. Evidence was found to be consistent across all studies, however, more work is needed in the area of fatigue as an 
injury mechanism during pitching. With a proof of concept established, the prevention of negative outcomes associated with fatigue must be the focus of future research and performance should not be the only criteria. 


\section{Manifestations of muscle fatigue in baseball pitchers: a 2 systematic review}

3

4

Richard Birfer ${ }^{1}$, Michael WL Sonne ${ }^{1,2}$, Michael WR Holmes ${ }^{1}$

1 Department of Kinesiology, Brock University, St. Catharines, Canada

2 Baseball Development Group, Toronto, Canada

11

12

*Corresponding Author:

Michael W.R. Holmes, PhD

14 Canada Research Chair in Neuromuscular Mechanics and Ergonomics

15 Assistant Professor

16 Brock University | Department of Kinesiology

17 Niagara Region | 1812 Sir Isaac Brock Way | St. Catharines, ON L2S 3A1

18 brocku.ca| Phone: 9056885550 x4398 | Fax: 9059844851

19 Email: michael.holmes@brocku.ca 


\section{Abstract}

22 Background. Fatigue in baseball pitchers is a process linked to lowered physical and mental

23 performance, injury, and changes in kinematics. Numerous studies have associated fatigue with

24 overuse, high ball velocities, lack of rest time, poor mechanics, and degree of self-satisfaction.

25 The aim of this study was to systematically review the literature to identify a theoretical

26 framework for the relationship between outcomes and the manifestation of fatigue on baseball

27 pitching. The synthesized data may identify areas requiring further research.

28 Methodology. This protocol was registered with PROSPERO (ID: CRD42018114194).

29 SPORTDiscus, Medline, PubMed, Cochrane Database of Systematic Reviews, and Google

30 Scholar were searched, using keywords such as fatigue in pitchers and changes in kinematics

31 (e.g. pitching mechanics, valgus elbow torque), performance (e.g. pitch count, pitch type), and

32 injury (e.g. pain, elbow and shoulder soreness). Three reviewers independently screened the

33 articles, selected relevant literature based on abstract eligibility, and assessed the methods

34 described therein for final inclusion.

35 Results. 31,860 articles were screened for eligibility and 25 articles were included for the

36 review. The selected articles included epidemiological, longitudinal, experimental, conference

37 papers, and laboratory studies. Evidence extracted from the 25 studies demonstrates a

38 relationship between fatigue in baseball pitching, and three overarching outcomes: changes in

39 kinematics, a decrease in performance, and an increase in injury risk.

40 Conclusions. Findings show that a co-dependence between changes in kinematics and a decrease

41 in performance, which stems from central and peripheral fatigue, is a contributing factor of

42 injury in baseball pitchers. A large percentage of baseball pitchers exhibit pain or soreness in

43 either their elbow or shoulder, or both at some point in a season. Initially, kinematic changes 
44 occur that could maintain performance, but may increase joint and tissue loading. Performance

45 decreased with elevated pitch counts and innings thrown, and pitching further into games or the 46 season. Evidence was found to be consistent across all studies, however, more work is needed in 47 the area of fatigue as an injury mechanism during pitching. With a proof of concept established, 48 the prevention of negative outcomes associated with fatigue must be the focus of future research 49 and performance should not be the only criteria. 
50

51

52

53

54

55

56

57

\section{Introduction}

The sport of baseball is commonly known as America's pastime. With its continued growth in participation since 2011 (Outdoor Participation Report, 2018), baseball is now played year-round. Pitchers of all ages often throw a large number of pitches throughout the calendar year (Fazarale, et al., 2012), which can result in the gradual accumulation of fatigue (broadly defined as a decrease in force generating capacity), if proper rest and recovery is not considered (Lyman, et al., 2001). Developmental baseball associations have set maximum pitch count recommendations for specific age groups, although an Internet-based survey confirmed that $27 \%$ of youth baseball coaches fail to follow these guidelines (Fazarale, et al., 2012). Numerous studies have further identified overuse (Makhni, et al., 2014), high velocities (Freeston, et al., 2014), lack of rest time (Crotin, et al., 2013), and pitch type (Lyman, et al., 2002), among others, as predictors/risk factors for fatigue; all of which are seemingly linked to kinematics, performance, tissue stress and injury.

The cumulative loading caused by fatigue can result in microtrauma, which over time, can contribute to the high prevalence of injury. One of the more prevalent injuries in baseball is a strain to the ulnar collateral ligament (UCL) (Yang et al., 2016), with recovery times for complete tears ranging from 12-to-15 months (Gossett, 2012). In the 2018 season, there were 86 cases of Tommy John surgeries across professional baseball (Roegele, 2018). An epidemiological study showed that $46 \%$ of youth pitchers were encouraged to throw through arm pain, while $82 \%$ of players reported arm fatigue during games and practices (Makhni, et al., 2014). With decreased time between pitches, fatigue reduces overall elbow joint stiffness, which can theoretically lead to increased stress on the UCL (Sonne \& Keir, 2016). Studies have demonstrated that maximal elbow valgus torque is produced during the arm cocked phase of 
73 pitching, when maximum shoulder external rotation is reached (Yang, et al., 2016). At this point,

74 a group of muscles, the flexor pronator mass, is a major contributor to providing the elbow with

75 the stability necessary to reduce stress on the UCL (Sonne \& Keir, 2016).

76 Muscle fatigue is a process that occurs due to central and/or peripheral mechanisms,

77 which can emerge due to numerous decrements from motor centers to the muscle fiber (Davis,

78 1995) and typically manifests as a decline in maximal force production (Enoka \& Duchateau,

79 2008). Changes in kinematics stemming from the onset of fatigue have been well documented. A

80 repeated-measures design was conducted on 16 healthy collegiate-level pitchers in which a

81 fatigue protocol was introduced (Tripp, Yochem \& Uhl, 2007). Following the fatigue protocol, it

82 was observed that sensorimotor system deficits recovered within four minutes for the elbow joint

83 and seven minutes for the scapulothoracic joint (Tripp, Yochem \& Uhl, 2007). The study also

84 showed that reproducibility of the glenohumeral segment during the arm-cocked phase of a

85 throw failed to recover within a 10-minute period. This emphasizes the importance of

86 sensorimotor acuity, proprioception and endurance in abduction and external rotation (Tripp,

87 Yochem \& Uhl, 2007). Two studies investigating college pitchers noted a decrease in elbow

88 flexion and an increase in hip flexion with greater season pitch count, contributing to an

89 increased joint load at the shoulder and the elbow (Grantham, et al., 2014; Yang et al., 2014).

90 Although many of these observed changes are indicators of fatigue, these kinematic changes may

91 not place additional tissue stress or joint loading on all pitchers, but act as protective

92 mechanisms.

93 Not all studies note changes in kinematics with fatigue. A controlled lab study directed

94 ten collegiate baseball pitchers to throw 15 pitches per inning in a seven to nine inning simulated

95 indoor game (Escamilla, 2007). The trunk moved significantly closer to a vertical position, 
96 however, pitching biomechanics remained very similar with the onset of fatigue, which was

97 inferred by a significant decrease in ball velocity (Escamilla, 2007). Two other studies identified

98 a decrease in velocity with accumulation of fatigue (Crotin, et al., 2016; Whiteside, et al., 2016),

99 but minimal changes in kinematics.

100 The literature independently supports that changes in kinematics and/or performance are

101 likely to result from fatigue while pitching. The exact mechanisms of how these changes

102 translate to injury is not entirely clear and the literature has mixed findings on the topic.

103 Therefore, the purpose of this study was to systematically review available literature in an

104 attempt to establish a link between kinematics, performance and injury during the manifestation 105 of muscle fatigue in baseball pitching.

\section{Methodology}

108 The review was conducted according to PRISMA (Preferred Reporting Items for Systematic

109 Reviews and Meta-Analyses) guidelines (Moher, et al., 2009) (Figure 1) and the protocol was

110 registered with PROSPERO (ID: CRD42018114194).

\section{Search Strategy}

113 Searches were conducted using four primary online databases, including SPORTDiscus,

114 Medline, PubMed, and Cochrane Database of Systematic Reviews. Google Scholar was a

115 secondary database used to acquire additional literature. Searches were designed with the help

116 of a librarian at Brock University. Articles were discovered using keywords including 'fatigue in

117 pitchers' and aspects describing 'kinematics' (pitching mechanics, throwing mechanics, valgus

118 elbow torque, joint stiffness, pitching kinematics), 'performance' (ball velocity, pitch count, 
119 pitch type, spin rate, overhead throwing, fatigue and performance), and 'injury' (elbow pain,

120 shoulder soreness, pitching injuries, fatigue and injuries, muscle fatigue, long-term injuries).

121 Given the nature of this review, an operational definition of fatigue was required to help

122 guide article selection and inclusion. For this work, fatigue was operationally defined as an

123 exercise induced loss in muscle force generating capacity. This can result in decreased strength

124 (Enoka \& Stuart, 1992; Fitts, 1994, Vollestad, 1997), joint stability (Webster \& Nussbaum,

125 2016), postural control (Gribble \& Hertel, 2004, Bizid, et al., 2009), and altered kinematics

126 (Apriantono, et al., 2006; Becker et al., 2017; Niederer, et al., 2016).

127

128 Eligibility Criteria

129 Studies were included if: they were published in the English language; they were peer

130 reviewed articles published in journals; they included baseball pitchers of various levels (junior,

131 high school, collegiate, or professional) and were gender specific towards males only. The

132 studies analyzed original research conducted within a laboratory or field-study setting.

133 Longitudinal, epidemiological, retrospective, experimental, conference papers, and crossover

134 laboratory studies were included (i.e., case reports, reviews, editorials, and letters were all

135 excluded). Articles were excluded if the study did not include baseball pitchers, therefore studies

136 examining a population of softball players or other overhead throwing athletes were not included

137 in the review.

138

139 Methodological Approach

140 After an initial screening for our inclusion and exclusion criteria and the removal of

141 duplicates (RB), three reviewers independently assessed the articles by screening abstracts (RB, 
142 MS, MH). Next, the full text of each article was obtained and screened against the exclusion

143 criteria. Each reviewer independently indicated the article as either "relevant", "irrelevant" or

144 "possibly relevant". Any disagreements were resolved through a consensus meeting between the

145 three reviewers, such that all remaining articles had complete agreement as "relevant".

146

147 Data Extraction

148 The relevant data was extracted from the included articles and the methods described

149 therein were assessed independently by three reviewers. All extracted results found in the

150 accompanying tables were performed by one reviewer (RB) and two reviewers (MS, MH) cross-

151 referenced and check the extracted data. The included data was extracted based on the category

152 of the article ( 3 categories were established, see below) and included: first author, year of

153 publication, study setting, number of pitchers included in the study, and outcome measure (e.g.

154 kinematic data, performance data, injury data).

155

156 Assessment of Methodological Quality

157 Methodological Quality was assessed using quality scores from the Downs and Black

158 Index (Downs \& Black, 1998). Data from the included articles were extracted from the following

159 categories: authors, year of publication, study purpose, design, population, statistical analysis,

160 and results. A criteria list was compiled, incorporating all of the selected articles used in this

161 systematic review, outlining each study. The Downs and Black assessment was chosen as it has

162 been validated and the original checklist could be modified for the needs of our systematic

163 review (Downs and Black, 1998). For this work, 13 items from the original checklist were

164 identified as relevant to this work. Each item was scored as either "yes" =1, "no" = 0, "unable to 
165 determine" $=\mathrm{U} / 0$. The scores from all 13 items were totaled to provide the quality score (Table $1661)$.

167

168

***Table $1 * * *$

169

170 Risk of Bias Assessment

171

An assessment of risk bias was determined based on the work of Lopes, et al. (2012) and

172 adapted by Ceyssens, et al. (2019). The criteria used by Lopes, et al. (2012) was adapted for our

173 work, with the scoring system based on the same 10 items: (1) definition of injury clearly

174 described, (2) prospective design that presents incidence or prevalence data, (3) description of

175 level of pitchers (e.g., recreational or professional level), (4) the process of inclusion of athletes

176 in the study was random (i.e., not by convenience) or the data collection was performed with the

177 entire target population; (5) data analysis performed with at least $80 \%$ of the athletes included in

178 the study; (6) injury data reported by pitchers; (7) same mode of injury data collection used; (8)

179 injury diagnosis conducted by a medical professional; (9) follow-up period of at least 6 months;

180 (10) incidence or prevalence rates of injury expressed by a ratio that represents both the number

181 of injuries as well as the exposure to pitching (Table 2).

182

183

$* * *$ Table $2 * * *$

184

185

186

187 
188 Results

189 Search Results

190 From the extensive database search, eligibility assessment was conducted on 31,860

191 articles based on their titles, abstracts, and if necessary, full-texts (Figure 1). Following the initial

192 screening process (based on title and abstract), 71 articles remained after which 6 duplicate

193 articles were removed, leaving 65 articles. After the completion of the secondary screening

194 process (agreement between all authors), a total of 29 articles were selected to be included for

195 the review. Of the 29 articles, four were removed because: 1) not a baseball study, 2) full-text

196 written in a foreign language, 3) full-text of the study (only abstract viewable) was not accessible

197 to the reviewers and 4) was a systematic review. The remaining 25 articles were included in this

198 review and were binned into three categories based on the studies focus - kinematics $(n=10)$,

199 performance $(n=13)$, and injury $(n=7)$. Note, some articles crossed into more than one category.

200 Given the timeline of our search, the earliest, most relevant study included within the review was

201 published in 2001 (Murray, et al., 2001), whereas the latest came from 2016 (Yang, et al., 2016).

202

203

$* * *$ Figure $1 * * *$

204

205

Methodological Quality and Bias Assessment

The scores from the modified Downs and Black checklist for each included article is

provided in Table 1. Quality scores ranged from 5 to 11 out of 13 (38-85\%). None of our

included articles were excluded on the basis of methodological quality. Scores on the modified risk bias scale from Lopes, et al. (2012) ranged from 3 to 9 out of 10. Of the included articles in

210 this systematic review, two received a score less than 5, which can be considered a high risk of 
211 bias (Ceyssens, et al., 2019). The remaining 23 articles received a low risk of bias score. Item 9

212 related to a follow-up period of at least 6 months received the lowest score, whereas item 2

213 relating to design received the highest score. All scores retrieved from the included articles can

214 be found in Table 2.

215

216 Participants and Study Design

217

The majority of the included studies assessed athletes at the junior (Freeston, et al., 2014;

218

Lyman, et al., 2001; Lyman, et al., 2002; Makhni, et al., 2014; Oliver, Weimar \& Henning, 2016;

219 Yang, et al., 2014), high school (Chou, et al., 2015; Crotin, et al., 2016; Erickson, et al., 2016;

220 Oliver \& Plummer, 2010; Yang, et al., 2014; Yang, et al., 2016 ), or collegiate level (Crotin, et

221 al., 2016; Dale, et al., 2007; Escamilla, et al., 2007; Grantham, et al., 2014; Keeley, Barber \&

222 Oliver, 2010; Mullaney, et al., 2005; Tripp, Yochem \& Uhl, 2007; Wang, et al., 2016; Warren,

223 Szymanski \& Landers, 2015) with reported mean age ranges from 8 to 23 years old. Five of the

22425 studies included professional baseball players (Bradbury \& Forman, 2012; Crotin, et al.,

225 2013; Mullaney, et al., 2005; Murray, et al., 2001; Sonne \& Keir, 2016; Whiteside, et al., 2016),

226 but an age range was only reported from one.

227

The prospective cohorts and longitudinal studies (Bradbury \& Forman, 2012; Lyman, et

228

al., 2001; Lyman et al., 2002) examined outcomes of workload across multiple seasons and the

229

decline in performance associated with the onset of fatigue. The epidemiological study used a

230

survey of youth baseball players to investigate arm pain (Makhni, et al., 2014). A cross-sectional

231 study (Yang et al., 2014), included a national survey of youth pitchers who self-reported risk-

232 prone activities. Furthermore, these studies assessed the effects of pitch type, pitching through

233 pain, and rest time on the manifestation of fatigue in baseball pitchers. Retrospective studies

Peer] reviewing PDF | (2018:12:33709:2:1:NEW 28 Jun 2019) 
234 included analysis of pitching records in minor league pitchers (Crotin et al, 2013) and publicly

235 available data on professional pitchers (Sonne \& Keir, 2016). Descriptive/controlled laboratory

236 studies analyzed kinematic changes in a pitcher's delivery with the accumulation of fatigue

237 (Chou, et al., 2015; Dale, et al., 2007; Erickson, et al., 2016; Escamilla, et al., 2007; Grantham, et

238 al., 2014; Keeley, et al., 2017; Mullaney, et al., 2005; Murray, et al., 2001; Oliver \& Plummer,

239 2010; Oliver, Weimar \& Henning, 2016; Tripp, Yochem \& Uhl, 2007; Wang, et al., 2016;

240 Warren, Szymanski \& Landers, 2015; Whiteside, et al., 2016). Randomized crossover studies

241 (Crotin, et al., 2014; Yang et al., 2016; Freeston, et al., 2014) included comparing the effects of

242 throwing exercises and identifying markers for arm fatigue (Freeston, et al., 2014), kinematic

243 analysis while altering stride length over multiple sessions (Crotin et al., 2014) and examining

244 the effects of rest intervals during a simulated game (Yang et al., 2016).

245

246 Main Findings

247 Evidence extracted from the 25 studies demonstrates a relationship between fatigue in

248 baseball pitching, and three overarching outcomes: changes in kinematics, a decrease in

249 performance, and an increase in injury risk. Each is discussed in more detail below.

250

251 Kinematic Changes

252 For this review, 10 of the 25 articles primarily assessed the relationship between kinematic

253 changes and fatigue in baseball pitching, mainly in the arm cocking and acceleration phase.

254 These changes are summarized in Table 3 . As fatigue accumulated in pitchers, significant

255 differences were seen in maximum shoulder external rotation (Erickson, et al., 2016; Mullaney, 
256 et al., 2005; Murray, et al., 2001), knee angle at ball release (Murray, et al., 2001) and hip-to-

257 shoulder separation (Erickson, et al., 2016), as well as, other changes highlighted in table 3.

258

259

$* * *$ Table $3 * * *$

260

261 Performance Changes

262 Pitching is an activity involving dynamic and high intensity muscle contractions, separated by

263 periods of rest in between pitches (Dale, et al., 2007). Pitch count, pitch type, ball velocity, and

264 rest time are among the main components that could either positively or negatively impact

265 performance on the mound. Table 4 summarizes the 13 studies that were identified as the fatigue

266 and performance changes category. A study associated decreased stride length with reduced

267 mean pitching heart rate, decreased pitching intensity, improved recovery capacity, and lowered

268 salivary cortisol from baseline (Crotin, et al., 2016). Accumulation of fatigue also accompanied

269 decreases in throwing accuracy (Wang, et al. 2016; Yang, et al., 2016) and future performance

270 (Bradbury \& Forman, 2012).

271

272

$* * *$ Table $4 * * *$

273

274 Fatigue linked to pain and injury

275 Pitching with discomfort, pitching through pain, and pitching with tiredness are three primary

276 cues or precursors to injury. Table 5 summarizes the 7 articles that were included in the fatigue

277 and pain/injury/discomfort category. A prospective cohort study found that elbow pain increased

278 significantly with slider usage, while shoulder pain increased significantly with curveball usage 
279 (Lyman, et al., 2002). Furthermore, multiple studies reported elbow and shoulder tiredness and 280 pain throughout a season (Lyman, et al., 2001; Lyman, et al., 2002; Yang, et al., 2014), which

281 were identified to be associated with decreased self-satisfaction and elevated pitch count

282 (Lyman, et al., 2001; Makhni, et al., 2014). A randomized crossover trial compared ball velocity

283 post-throwing and post-running programs, and while each program led to a significant increase

284 in arm soreness, there was a larger increase in ball velocity following the throwing program 285 (Freeston, et al. 2014).

286

287

***Table $5 * * *$

288

289

\section{Discussion}

290

Following an extensive screening process, evidence was drawn from longitudinal,

291 retrospective, epidemiological, experimental and laboratory studies. To our knowledge, this is

292 the first review to extract evidence from available literature and systematically identify a

293 relationship between kinematics, performance, and injury during the manifestation of muscle

294 fatigue in baseball pitchers. The main findings of this systematic review identified a co-

295 dependence between changes in kinematics to delay a decrease in performance, which could

296 result in an increased risk of musculoskeletal injury (Figure 2).

297

298

$* * *$ Figure $2 * * *$

299

300

This work suggests that changes in performance likely decay at a lesser rate than changes

301 in kinematics, suggesting that modifications to a pitcher's kinematics are made to limit the

302 decrements of fatigue. The compromise for maintaining performance is the adaptation of 
303 mechanics which could increase the risk of musculoskeletal injury, particularly with respect to

304 the elbow and shoulder joints. Many of the studies examined in this review also included

305 measures of muscle activity via electromyography (EMG). While EMG can be loosely used as a

306 surrogate indicator of force (Roberts \& Gabaldon, 2008) it is also an indicator of muscle fatigue

307 (typically represented by increases in EMG amplitude and decreases in mean and median power

308 frequency). Surface electromyography is the recording of electrical signals transmitted from the

309 brain to the neuromuscular junction, resulting in the contraction of the muscle, and the

310 production of a force at the end effector (Dowling, 1997; De Luca, 1997). While consideration

311 must be made surrounding factors of movement, fatigue, skin impedance, and a variety of other

312 physiological and environmental factors related to the interpretation of EMG, the use of surface

313 EMG in sports is a non-invasive method of predicting internal forces as a result of human

314 movement (Clarys, et al., 2010). There are challenges with inferring the results from EMG

315 during pitching, particularly with changes in kinematics. During such a dynamic activity, the

316 EMG signal must be interpreted with caution of the potential limitations, such as the electrode

317 position over the muscle belly changing during rapid, ballistic movements - particularly when a

318 change in kinematics results in different limb position identified during a specific position during

319 the throwing motion. As a result, it is difficult to identify if these studies have seen an increase in

320 EMG activity as a result of increased motor unit recruitment due to fatigue, a requirement for

321 increased muscle force, or due to the nature of EMG limitations during dynamic movements.

322 Muscle fatigue reduces the force generating capacity of the elbow and shoulder muscles, thus

323 compromising the potential to maintain joint stability, and thus, injury risk increases. This work

324 summarizes the changes in kinematics, performance and injury risk as a result of fatigue, while

325 acknowledging the difficulty of direct fatigue measures. 
326 Kinematic Changes

327 Changes in kinematics are a primary outcome of pitching-induced muscle fatigue (Table

328 3). With the accumulation of muscle fatigue, trunk flexion is altered during the arm cocking and

329 acceleration phase (from $34 \pm 12^{\circ}$ to $29 \pm 11^{\circ}$ ), as well as observed changes in shoulder and

330 elbow kinetics, all of which can increase the risk of injury in pitchers (Escamilla, et al., 2007).

331 After the implementation of fatigue protocols in laboratory settings, recovery time varied for the

332 scapulothoracic, wrist, elbow, and glenohumeral joints wherein the latter took an extended

333 amount of time to recover (Tripp, Yochem \& Uhl, 2007). Moreover, these kinematic changes

334 may partly be explained by decreases in triceps muscle activity, and an increase in activity for

335 the biceps and deltoids as pitchers reached fatigue (Oliver \& Plummer, 2010). Other noted signs

336 of kinematic changes with the onset of fatigue are small, yet potentially significant, increases in

337 knee flexion (from $53.6 \pm 21.5^{\circ}$ to $56.1 \pm 22.2^{\circ}$ ) and forward trunk tilt at the instant of ball

338 release (Chou, et al., 2015). With the accumulation of innings, significant decreases in maximal

339 shoulder external rotation, knee angle at ball release, and elbow flexion have been observed as a

340 pitcher becomes fatigued (Grantham, et al., 2014; Murray, et al., 2001). A controlled laboratory

341 study of a simulated baseball game suggested that collegiate pitchers maintain their kinematics

342 throughout the duration of a game, despite fatigue (Escamilla et al. 2007). Escamilla et al. (2007)

343 found that trunk kinematics changed, yet other kinematic and kinetic variables were unaffected.

344 The authors did note that a more rigorous fatigue protocol may provide additional insight.

345 However, even slight deviations from a pitcher's optimal kinematic patterns, due to the

346 manifestation of fatigue, or pitching in a fatigued state for a longer period of time, may increase

347 the risk of injury in pitchers (Chalmers, et al., 2017; Escamilla et al. 2007). These kinematic

348 changes may serve as a precursor to changes in performance, and eventual injury risk. 


\section{Kinetic Changes}

350 Changes in kinematics would in turn lead to changes in kinetics, as the body attempts to

351 compensate for the negative effects instigated by the accumulation of muscular fatigue. After

352 videotaping seven major league pitchers for multiple innings, changes in kinematics led to

353 decreases in maximum distraction forces at both the shoulder (from $97 \%$ of body weight in the

354 first inning to $88 \%$ of body weight in the last) and elbow (from $85 \%$ of body weight in the first

355 and $72 \%$ of body weight in the last), and horizontal adduction torque at ball release and

356 maximum horizontal abduction torque (from $5 \%$ and $11 \%$ of body weight, respectively in the

357 first inning, down to $4 \%$ and $8 \%$ of body weight in the last inning), but ball velocity did

358 ultimately decrease by $5 \mathrm{mph}$ (Murray, et al., 2001). A study assessing the contribution of

359 forearm flexor muscles during pitching noted that peak flexor carpi ulnaris muscle activity was

360 significantly greater during fastballs post a fatigue protocol during the acceleration phase of the

361 pitching motion to provide more stability for the wrist joint (confidence interval: $0.49-2.05 ; \mathrm{p}=$

$3620.02 ; \mathrm{d}=1.27$ ) (Wang, et al, 2016). A separate study examined the importance of stabilizing the

363 wrist, identifying peak flexor carpi ulnaris muscle activity to be significantly greater for the

364 fastball post-fatigue protocol during the acceleration phase of the pitch. Since both the flexor

365 carpi ulnaris and radialis muscles attach to the medial side of the elbow, the accumulation of

366 fatigue may negatively affect the ulnar nerve (Wang, et al., 2016). In addition to the noted work

367 that highlighted wrist flexor muscle fatigue, a retrospective analysis identified that the greatest

368 muscle fatigue during a game occurs in the extensor carpi radialis (Sonne \& Keir, 2016).

369 However, the authors also acknowledged that elevated fatigue in the wrist flexors

370 (predominantly flexor digitorum superficialis and pronator teres), are noteworthy, given their

371 large contribution to stabilize the elbow and counter valgus torque. With an increase in muscle 
372 fatigue, there will be a reduction in overall elbow joint stiffness, which can ultimately increase

373 the likelihood of an UCL injury (Sonne \& Keir, 2016). While this review aimed to evaluate

374 directly measurable outcomes in kinematics and performance, it is acknowledged that a more in-

375 depth evaluation of kinetics (which are typically more difficult to quantify than kinematics and

376 even more challenging to quantify in a fatigued state), in relation to changes in kinematics, is a

377 valuable next step.

378 Performance Changes

379 Numerous studies have noted that changes in kinematics during a baseball game (due to

380 fatigue) can lead to a significant decrease in ball velocity and therefore can impact performance

381 (Whiteside, et al., 2016). Furthermore, retrospective analysis studies have not only confirmed a

382 decrease in ball velocity due to fatigue, but have also provided evidence that with each pitch

383 thrown in the preceding game, there is a significant increase in earned run average (ERA) and

384 the home run rate with each pitch thrown (Crotin, et al., 2013; Bradbury \& Forman, 2012).

385 Alternatively, Keeley, et al. (2017) identified the effect of fatigue on throwing accuracy (Table

386 4). After a sample of 14 youth pitchers were recruited for the study, results showed that both

387 total strike percentage and first pitch strike percentage decreased at a perceived fatigue level of

388 'moderate' (52.4\% and 49.8\%) and further at the 'severely' fatigued (45.3\% and $40.0 \%)$

389 perceived level (Keeley, et al., 2017).

390 A separate study showed the proportion of hard-thrown (fastball type) pitches in the

391 seventh inning decreased compared to the first inning and pitchers threw more off-speed and

392 breaking pitches later in games (Whiteside, et al., 2016). These findings are supported further by

393 Whiteside (2016), which showed that pitchers tend to compensate for fatigue in later innings, by

394 throwing fewer hard pitches and more offspeed and breaking pitches. Pitchers with a wider 
395 repertoire of pitches see more changes in muscle activity patterns with different pitch types,

396 therefore lowering risk of elbow injury due to overuse and fatigue (Whiteside, et al., 2016).

397 Alternating task types and increasing the variability of biomechanical exposures to the human

398 body has been hypothesized as an injury prevention intervention in ergonomics research

399 (Srinivasan \& Mathiassen, 2012), and may serve as an explanation for the protective effect of

400 having more pitch types. Nevertheless, these findings are important for attempting to not only

401 quantify effects of fatigue on performance, but how changes in kinematics due to the

402 manifestation of fatigue can influence overall performance.

403

404 Fatigue linked to injury

405 Fatigue has been related to changes in full body kinematics, in particular to the elbow and

406 shoulder, which, when combined with poor recovery, can decrease tissue tolerance and increase

407 the risk of injury in baseball pitchers (Oliver \& Plummer, 2010). Current literature has derived

408 evidence that the accumulation of fatigue during pitching can lead to elbow and shoulder

409 discomfort, pain, and/or injury. Risk of injury is known to increase with age and level of

410 competition, because of microtrauma, insufficient rest, and overuse associated with continuous

411 throwing. In fact, one longitudinal study reported $23 \%$ of little league players have identified

412 prior overuse injuries (Lyman, et al., 2001). Risk of injury has also been linked to pitch type, as

413 multiple studies have shown the use of curveballs and sliders contributes to an increased risk of

414 shoulder and elbow injuries (Lyman, et al., 2001; Yang, et al., 2014). Moreover, pitchers have

415 reported being encouraged to pitch through arm fatigue and pain/discomfort on several occasions

416 during the span of a season, which increases the likelihood of an eventual injury (Lyman, et al.,

417 2001). A limitation of available studies is the prevalence of bias due to the use of self-report 
418 criteria. Interviews were conducted and questionnaires were asked to be completed

419 independently, which led to subjective responses amongst the population. In experimental and

420 laboratory studies, the Borg scale was incorporated to allow the subjects to subjectively rate their

421 perceived level of exertion, while follow-up questionnaires and telephone interview were

422 conducted following competition in on-field case studies (Lyman, et al., 2001; Makhni, et al.,

423 2014; Lyman, et al., 2002; Yang, et al., 2014). While survey and subjective fatigue measures

424 must be met with caution when distinguishing a definitive link between fatigue and injury risk in

425 pitchers, our work suggests evidence of such. This is in agreement with a review by Bruce and

426 Andrews (2014) who identified fatigue as a mechanism for injury of the UCL, as well as work by

427 Fleisig, et al. (2009) who reported that pitchers who threw with regular arm fatigue were 36

428 times more likely to sustain an injury.

429 It must be noted that pain and discomfort does not always suggest injury and

430 biomechanical damage to a tissue does not always suggest that an individual will experience

431 pain. Our work highlights that fatigue may increase the risk of injury, but is not necessarily a

432 direct link to injury for all individuals. The work by Lyman et al. (2001 and 2002) are some of

433 the only studies to establish a link between fatigue and pain, with inferences to injury. Our search

434 criteria mostly included work from junior and collegiate athletes, rather than professional

435 athletes (although some papers did include this data) and this should be noted as a confounding

436 variable when linking fatigue to injury. Clearly, more work is needed in the area of fatigue as an

437 injury mechanism during pitching. Despite the differences in biomechanical reporting of

438 kinematic and kinetic data during pitching studies, a meta-analysis would help determine true

439 effects of kinematic and kinetic changes due to fatigue and would aid in the establishment of a

440 proper fatigue-injury paradigm. 


\section{Conclusions}

442 This review has extracted evidence from longitudinal, retrospective, epidemiological, 443 experimental and laboratory studies, deducing a co-dependence between changes in kinematics 444 and a decrease in performance, stemming from the manifestation of fatigue. This can indirectly 445 suggest, despite the few longitudinal studies that have directly investigated it, that there is a 446 relationship between fatigue and increased risk of injury. To our knowledge, this is the first

447 review of its kind to holistically explore and summarize the literature on the multi-faceted impact 448 of muscle fatigue as it relates to pitching. With a proof of concept now established, the 449 prevention of the negative outcomes of fatigue must be the focus of future research as it is 450 imperative to protect pitchers at all age levels. This work provides insight into how the physical 451 demands of pitching can influence kinematics, performance and potential injury. Specific 452 markers have been identified (kinematic and performance based) that might suggest overloading 453 and additional recovery would be required. 


\section{References}

460 Apriantono T, Nunome H, Ikegami Y, Sano S. 2006. The Effect of Muscle Fatigue on Instep 461 Kicking Kinetics and Kinematics in Association Football. Journal of Sports Sciences. 24:951-60.

462 Becker S, Frohlich M, Kelm JM, Ludwig O. 2017. Change of Muscle Activity as Well as 463 Kinematic and Kinetic Parameters During Headers After Core Muscle Fatigue. Sports, 5:10. 464 Bizid R, Margnes E, Francois Y, Jully JL, Gonzalez GZ, Dupui P, Paillard T. 2008. Effects of 465 Knee and Ankle Muscle Fatigue on Postural Control in the Unipedal Stance. European Journal 466 of Applied Physiology, 106:375-380.

467 Bradbury JC, Forman SL. 2012. The Impact of Pitch Counts and Days of Rest on Performance 468 Among Major-League Baseball Pitchers. The Journal of Strength and Conditioning Research, 469 26:1181-1187, DOI: 10.1519/JSC.0b013e31824e16fe.

470 Bruce JR \& Andrews JR. 2014. Ulnar Collateral Ligament Injuries in the Throwing Athlete. 471 Journal of the American Academy of Orthopaedic Surgeons, 22:315-25.

472 Ceyssens L, Vanelderen R, Barton C, Malliaras P, Dingenen B. 2019. Biomechanical Risk 473 Factors Associated With Running-Related Injuries: A Systematic Review. Journal of Sports 474 Medicine. 1-21. DOI: 10.1007/s40279-019-01110-z.

475 Chalmers PN, Wimmer MA, Verma NN, Cole BJ, Romeo AA, Cvetanovich GL, Pearl ML. 476 2017. The Relationship Between Pitching Mechanics and Injury: A Review of Current Concepts.

477 Sports Health, 9:216-221.

478 Chou P, Huang YP, Gu YH, Liu C, Chen SK, Hsu KC, Wang RT, Huang MJ, Lin HT. 2015.

479 Change in Pitching Biomechanics in the Late-Inning in Taiwanese High School Baseball

480 Pitchers. The Journal of Strength and Conditioning Research, 29:1500-08, DOI:

$481 \quad 10.1519 / \mathrm{JSC} .0000000000000791$. 
482 Clarys JP, Scafoglieri A, Tresignie J, Reilly T, Roy PV. 2010. Critical Appraisal and Hazards of

483 Surface Electromyography Data Acquisition in Sport and Exercise. Asian Journal of Sports 484 Medicine. 2:69-80.

485 Crotin RL, Bhan S, Karakolis T, Ramsey DK. 2013. Fastball Velocity Trends in Short-Season 486 Minor League Baseball. The Journal of Strength and Conditioning Research, 27:2206-2212, 487 DOI: 10.1519/JSC.0b013e31827e1509.

488 Crotin RL, Kozlowski K, Horvath P, Ramsey DK. 2014. Altered Stride Length in Response to 489 Increasing Exertion among Baseball Pitchers. Medicine and Science in Sports and Exercise, 490 46:565-571, DOI: 10.1249/MSS.0b013e3182a79cd9.

491 Dale BR, Kovaleski JE, Ogletree T, Heitman RJ, Norrell PM. 2007. The Effects of Repetitive 492 Overhead Throwing on Shoulder Rotator Isokinetic Work-Fatigue. North American Journal of 493 Sports Physical Therapy, 2:74-80.

494 Davis MJ, C. 1995. Central and Peripheral Factors in Fatigue. Journal of Sports Sciences. 495 13:49-53, DOI: 10.1080/02640419508732277

496 De Luca CJ. 1997. The Use of Surface Electromyography in Biomechanics. Journal of Applied 497 Biomechanics. 13:135-163.

498 Dowling JJ. 1997. The Use of Electromyography for the Noninvasive Prediction of Muscle 499 Forces. Sports Medicine. 24:82-96

500 Downs SH, Black N. 1998. The Feasibility of Creating a Checklist for the Assessment of the 501 Methodological Quality both of Randomised and Non-Randomised Studies of Health Care 502 Intervention. Journal of Epidemiology Community Health, 52:377-84.

503 Erickson BJ, Sgori T, Chalmers PN, Vignona P, Lesniak M, Bush-Joseph CA, Verma NN, 504 Romeo AA. 2016. The Impact of Fatigue on Baseball Pitching Mechanics in Adolescent Male 
505 Pitchers. Arthroscopy: The Journal of Arthroscopic and Related Surgery, 32-762-771. DOI:

506 10.1016/j.arthro.2015.11.051.

507 Escamilla RF, Barrentine SW, Fleisig GS, Zheng H, Takada Y, Kingsley D, Andrews JR. 2007.

508 Pitching Biomechanics as a Pitcher Approaches Muscular Fatigue During a Simulated Baseball

509 Game. The American Journal of Sport Medicine, 35:23-33, DOI: 10.1177/0363546506293025.

510 Enoka RM, Duchateau J. 2008. Muscle Fatigue: What, Why, and How It Influences Muscle

511 Function. The Journal of Physiology. 586:11-23.

512 Enoka RM, Stuart DG. 1992. Neurobiology of Muscle Fatigue. Journal of Applied

513 Physiological. 72:1631-48.

514 Fazarale JJ, Magnussen RA, Pedroza AD, Kaeding CC. 2012. Knowledge of Compliance with

515 Pitch Count Recommendations: A Survey of Youth Baseball Coaches. Sports Health, 4:202-20,

516 DOI: $10.1177 / 1941738111435632$.

517 Fitts RH. 1994. Cellular Mechanisms of Muscle Fatigue. Physiological Reviews. 74:49-94.

518 Fleisig GS, et al. 2009. Prevention of Elbow Injuries in Youth Baseball Pitchers. Current Sports

519 Medicine, 8:250-54.

520 Freeston J, Adams R, Ferdinands RE, Rooney K. 2014. Indicators of Throwing Arm Fatigue in

521 Elite Adolescent Male Baseball Players: A Randomized Crossover Trial. The Journal of Strength

522 and Conditioning Research, 28:2115-2120, DOI: 10.1519/JSC.0000000000000395.

523 Gossett W. 2012. Tommy John Surgery Rehabilitation to Take a Year. Times Free Press.

524 Retrieved from Georgia Sports Orthopedic Specialists Centre.

525 Grantham JW, Byram IR, Meadows MC, Ahmad CS. 2014. The Impact of Fatigue on the

526 Kinematics of Collegiate Baseball Pitchers. The Orthopaedic Journal of Sports Medicine, 2:1-

527 10, DOI: 10.1177/2325967114537032. 
528 Gribble PA, Hertel J. 2004. Effect of Lower-Extremity Muscle Fatigue on Postural Control.

529 Archives of Physical Medicine and Rehabilitation. 85:589-92.

530 Holmes M, Sonne M, Birfer R. Changes in kinematics and performance due to fatigue in

531 baseball pitching: a systematic review. PROSPERO: International prospective register of

532 systematic reviews. ID: CRD42018114194. 2018.

533 Keeley D, Barber K, Oliver GD. 2010. Comparison of Pelvis Kinematics During the Baseball

534 Pitch: Fatigued and Non-Fatigued Conditions. Available at https://ojs.ub.uni-

535 konstanz.de/cpa/article/view/4598/4285. $28^{\text {th }}$ International Conference on Biomechanics in

536 Sports (2010).

537 Keeley D, Oliver DG, Torry M, Wicke J. 2017. Validity of Pitch Velocity and Strike Percentage

538 to Assess Fatigue in Young Baseball Pitchers. International Journal of Performance Analysis in 539 Sport, 29:355-366. DOI: 10.1080/24748668.2014.11868727.

540 Lopes AD, Hespanhol LC, Yeung SSM, Costa LOP. 2012. What are the Main Running-Related

541 Musculoskeletal Injuries? A Systematic Review. Journal of Sport Medicine. 42:891-905.

542 Lyman S, Fleisig GS, Waterbor JW, Funkhouser EM, Pulley L, Andrews JR, Osinski ED,

543 Roseman JM. 2001. Longitudinal Study of Elbow and Shoulder Pain in Youth Baseball

544 Pitchers. Medicine and Science in Sports and Exercise 33:1803-1810.

545 Lyman S, Fleisig JR, Andrews JR, Osinski ED. 2002. Effect of Pitch Type, Pitch Count, and

546 Pitching Mechanics on Risk of Elbow and Shoulder Pain in Youth Baseball Pitchers. The

547 American Journal of Sport Medicine, 30:463-468, DOI: 10.1177/03635465020300040201.

548 Makhni EC, Morrow ZS, Luchetti TJ, Mishra-Kalyani PS, Gualtieri AP, Lee RW, Ahmad CS.

549 2014. Arm Pain in Youth Baseball Players a Survey of Healthy Players. The

550 American Journal of Sport Medicine, 43:41-46, DOI: 10.1177/0363546514555506. 
551 Moher D, Liberati A, Tetzlaff J, Altman DG, 2009. Preferred Reporting Items for Systematic

552 Reviews and Meta-analyses: The PRISMA Statement. PLOS Medicine. 6.

553 Mullaney MJ, McHugh MP, Donofrio TM, Nicholas SJ. 2005. Upper and Lower Extremity

554 Muscle Fatigue After a Baseball Pitching Performance. The American Journal of Sport

555 Medicine, 33:108-13, DOI: 10.1177/0363546504266071.

556 Murray TA, Cook TD, Werner SL, Schlegel TF, Hawkins RJ. 2001. The Effects of Extended Play

557 on Professional Baseball Pitchers. The American Journal of Sport Medicine, 29:137-42.

558 Oliver GD, Plummer H. 2010. Quantifying SEMG in Pre-Fatigue and Fatigue States During the

559 Fastball Baseball Pitch. Available at https://ojs.ub.uni-konstanz.de/cpa/article/view/4500. 28 ${ }^{\text {th }}$

560 International Conference on Biomechanics in Sports (2010).

561 Niederer SA, et al. 2016. Local Muscle Fatigue and 3D Kinematics of the Cervical Spine in

562 Healthy Subjects. The Journal of Motor Behavior. 48:491-497.

563 Oliver GD, Weimar WH, Henning LE. 2016. Effects of a Simulated Game on Muscle Activation

564 in Youth Baseball Pitchers. The Journal of Strength and Conditioning Research, 30:415-420,

565 DOI: $10.1519 / \mathrm{JSC} .0000000000001130$.

566 Outdoor Participation Report. 2018. Number of Participants in Baseball in the United States

567 from 2006 to 2017 (in Millions). https://www.statista.com/statistics/191626/participants-in-

568 baseball-in-the-us-since-2006/ (accessed 5 August 2018).

569 Passan, J. 2016. The Arm: Inside the Billion-Dollar Mystery of the Most Valuable Commodity in

570 Sports. Retrieved from MLBTradeRumours.

571 Roberts TJ, Gabaldon AM. 2008. Interpreting Muscle Function from EMG: Lessons Learned

572 from Direct Measurements of Muscle Force. Oxford Journals. 48:312-320.

573 Roegele, J. 2018. Tommy John Surgery List. Hardball Times. 
574 Sonne MWL, Keir PJ. 2016. Major League Baseball Pace-of-Play Rules and Their Influence on

575 Predicted Muscle Fatigue During Simulated Baseball Games. Journal of Sport Sciences,

576 34:2054-2062, DOI: 10.1080/02640414.2016.1150600.

577 Srinivasan D, Mathiassen SE. 2012. Motor variability in occupational health and

578 performance. Clinical biomechanics, 27:979-993.

579 Tripp BL, Yochem EM, Uhl TL. 2007. Functional Fatigue and Upper Extremity Sensorimotor

580 System Acuity in Baseball Athletes. Journal of Athletic Training, 42:90-98.

581 Vollestad NK. 1997. Measurement of Human Muscle Fatigue. Journal of Neuroscience Methods. $582 \quad 74: 219-27$.

583 Wang L-H, Lo KC, Jou IM, Kuo LC, Tai TW, Su FC. 2016. The Effects of Forearm Fatigue on

584 Baseball Fastball Pitching, With Implications About Elbow Injury. Journal of Sports Sciences, 585 34:1182-1189, DOI: 10.1080/02640414.2015.1101481.

586 Warren CD, Szymanski DJ, Landers MR. 2015. Effects of Three Recovery Protocols on Range

587 of Motion, Heart Rate, Rating of Perceived Exertion, and Blood Lactate in Baseball Pitchers

588 During a Simulated Game. The Journal of Strength and Conditioning Research, 29:3015-3025,

589 DOI: $10.1519 / \mathrm{JSC} .0000000000000487$.

590 Webster CA, Nussbaum, MA. 2016. Localized Ankle Fatigue Development and Fatigue

591 Perception in Adults With or Without Chronic Ankle Instability. Journal of Athletic Training. $592 \quad 51: 491-97$.

593 Whiteside D, Martini DN, Zernicke RF, Goulet GC. 2016. Changes in a Starting Pitcher's

594 Performance Characteristics Across the Duration of a Major League Baseball Game.

595 International Journal of Sports Physiology and Performance, 11:247-254, DOI:

596 10.1123/ijspp.2015-0121. 
597 Yang J, Mann BJ, Guettler JH, Dugas JR, Irrgang JJ, Fleisig GS, Albright JP. 2014. Risk-Prone 598 Pitching Activities and Injuries in Youth Baseball: Findings from a National Sample. The 599 American Journal of Sport Medicine, 42:1456-1463, DOI: 10.1177/0363546514524699.

600 Yang S-C, Wang CC, Lee SD, Lee YU, Chan KH, Chen YL, Fogt DL, Kuo CH. 2016. Impact of 601 12-s Rule on Performance and Muscle Damage of Baseball Pitchers. Medicine and Science in 602 Sports and Exercise, 48:2512-2516, DOI: 10.1249/MSS.0000000000001048. 
Figure 1

PRISMA flowchart

PRISMA flow chart for search and article screening process.

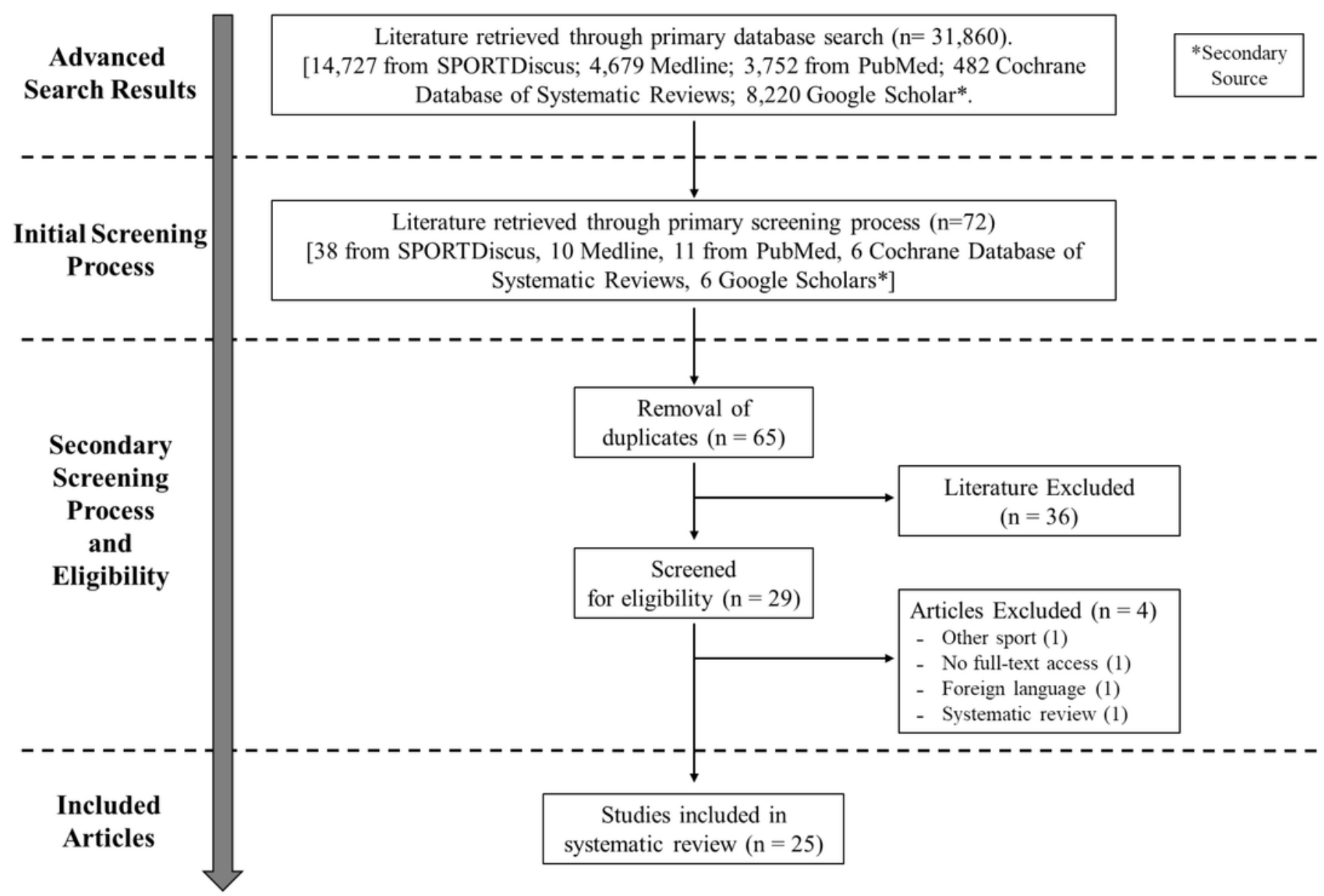


Figure 2

Theoretical framework summary

Theoretical framework representing the relationship between fatigue and our three identified outcomes. 


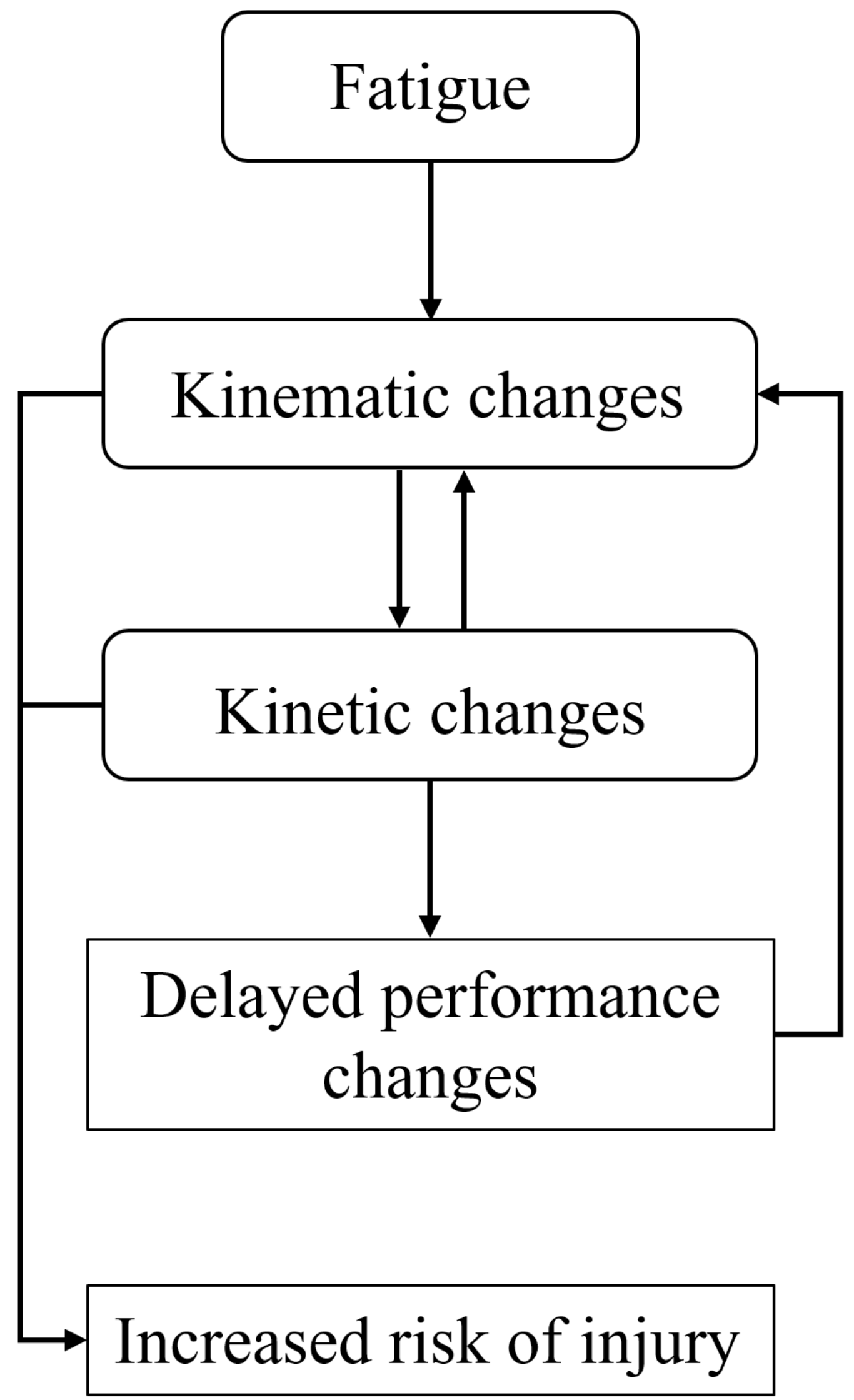




\section{Table $\mathbf{1}$ (on next page)}

Methodological quality assessment

Methodological quality assessment via Modified Downs and Black quality index. 
2 Table 1. Methodological quality assessment via Modified Downs and Black quality index

\begin{tabular}{|c|c|c|c|c|c|c|c|c|c|c|c|c|c|c|}
\hline \multirow[t]{2}{*}{ Included Studies } & \multicolumn{14}{|c|}{ Modified Downs and Black checklist number } \\
\hline & 1 & 2 & 3 & 6 & 7 & 9 & 10 & 11 & 12 & 16 & 18 & 20 & 26 & Total \\
\hline Bradbury \& Forman (2012) & 1 & 1 & 1 & 1 & 1 & 0 & 0 & 1 & 1 & $\mathrm{U}$ & 1 & 1 & 0 & 9 \\
\hline Chou et al. (2015) & 1 & 1 & 1 & 1 & 1 & 0 & 1 & 0 & 0 & $\mathrm{U}$ & 1 & 1 & 0 & 8 \\
\hline Crotin et al. (2013) & 1 & 1 & 1 & 1 & 1 & 0 & 1 & 0 & 0 & $\mathrm{U}$ & 1 & 1 & 0 & 8 \\
\hline Crotin et al. (2014) & 1 & 1 & 1 & 1 & 1 & 0 & 1 & 0 & 0 & $\mathrm{U}$ & 1 & 1 & 0 & 8 \\
\hline Dale et al. (2007) & 1 & 1 & 1 & 1 & 1 & 0 & 1 & 0 & 0 & $\mathrm{U}$ & 1 & 1 & 0 & 8 \\
\hline Erickson et al. (2016) & 1 & 1 & 1 & 1 & 1 & 0 & 1 & 0 & 0 & $\mathrm{U}$ & 1 & 1 & 0 & 8 \\
\hline Escamilla et al. (2007) & 1 & 1 & 1 & 1 & 1 & 0 & 1 & 0 & 0 & $\mathrm{U}$ & 1 & 1 & 0 & 8 \\
\hline Freeston et al. (2014) & 1 & 1 & 1 & 1 & 1 & 0 & 1 & 0 & 0 & $\mathrm{U}$ & 1 & 1 & 0 & 8 \\
\hline Grantham et al. (2014) & 1 & 1 & 0 & 1 & 1 & 0 & 1 & 0 & 0 & $\mathrm{U}$ & 1 & 0 & 0 & 6 \\
\hline Keeley, Barber \& Oliver (2010) & 1 & 1 & 1 & 1 & 1 & 0 & 0 & 0 & 0 & $\mathrm{U}$ & $\mathrm{U}$ & 1 & 0 & 6 \\
\hline Keeley et al. (2017) & 1 & 1 & 1 & 1 & 1 & 0 & 1 & 0 & 0 & $\mathrm{U}$ & $\mathrm{U}$ & 1 & 0 & 7 \\
\hline Lyman et al. (2001) & 1 & 1 & 1 & 1 & 1 & 1 & 1 & 1 & 1 & $\mathrm{U}$ & 1 & 1 & 0 & 11 \\
\hline Lyman et al. (2002) & 1 & 1 & 1 & 1 & 1 & 0 & 1 & 1 & 1 & $\mathrm{U}$ & 1 & 1 & 0 & 10 \\
\hline Makhni et al. (2014) & 1 & 1 & 1 & 1 & 1 & 0 & 1 & 1 & 1 & $\mathrm{U}$ & 1 & 1 & 0 & 10 \\
\hline Mullaney et al. (2005) & 1 & 1 & 1 & 1 & 1 & 0 & 1 & 0 & 0 & $\mathrm{U}$ & 1 & 1 & 0 & 8 \\
\hline Murray et al. (2001) & 1 & 1 & 1 & 1 & 1 & 0 & 1 & 0 & 0 & $\mathrm{U}$ & 1 & 1 & 0 & 8 \\
\hline Oliver \& Plummer (2010) & 1 & 0 & 1 & 0 & 1 & 0 & 1 & 0 & 0 & $\mathrm{U}$ & 1 & 0 & 0 & 5 \\
\hline Oliver, Wiemar \& Henning (2016) & 1 & 0 & 1 & 0 & 1 & 0 & 1 & 0 & 0 & $\mathrm{U}$ & 1 & 0 & 0 & 5 \\
\hline Sonne \& Keir (2016) & 1 & 1 & 1 & 1 & 1 & 0 & 1 & 0 & 0 & $\mathrm{U}$ & 1 & 1 & 0 & 8 \\
\hline Trip, Yochem \& Uhl (2007) & 1 & 1 & 1 & 1 & 1 & 0 & 1 & 0 & 0 & $\mathrm{U}$ & 1 & 1 & 0 & 8 \\
\hline Wang et al. (2016) & 1 & 1 & 1 & 1 & 1 & 0 & 1 & 0 & 0 & $\mathrm{U}$ & 1 & 1 & 0 & 8 \\
\hline Warren, Szymanski \& Landers (2015) & 1 & 1 & 1 & 1 & 1 & 0 & 1 & $\mathrm{U}$ & $\mathrm{U}$ & $\mathrm{U}$ & 1 & 1 & 0 & 8 \\
\hline Whiteside et al. (2016) & 1 & 1 & 1 & 1 & 1 & 0 & 0 & 0 & 0 & $\mathrm{U}$ & 1 & 1 & 0 & 7 \\
\hline Yang et al. (2014) & 1 & 1 & 1 & 1 & 1 & 0 & 1 & 1 & 1 & $\mathrm{U}$ & 1 & 1 & 0 & 10 \\
\hline Yang et al. (2016) & 1 & 1 & 1 & 1 & 1 & 0 & 1 & 0 & 0 & $\mathrm{U}$ & 1 & 1 & 0 & 8 \\
\hline
\end{tabular}


5 (7) random variability of main outcomes provided, (9) characteristics of patients lost to follow-up described, (10) actual probability values reported, (11) subjects asked to participate representative of entire population, (12) subjects prepared to participate representative of entire population, (16) clear mentioning of data dredging (unplanned analysis), (18) appropriate statistical analysis, (20) valid and reliable outcome measures, (26) patients lost to follow-up taken into account. Note: Only the Downs and Black questions that applied to this work were assessed. 


\section{Table 2 (on next page)}

\section{Risk of bias}

Risk of bias assessment related to included studies (modified from Lopes et al. 2012). 
2 Table 2. Risk of bias assessment related to included studies (modified from Lopes et al. 2012).

\begin{tabular}{|c|c|c|c|c|c|c|c|c|c|c|c|}
\hline \multirow[t]{2}{*}{ Included Studies } & \multicolumn{11}{|c|}{ Criteria } \\
\hline & 1 & 2 & 3 & 4 & 5 & 6 & 7 & 8 & 9 & 10 & Total \\
\hline Bradbury \& Forman (2012) & 0 & 1 & 1 & 1 & 1 & 0 & 0 & 0 & 0 & 0 & 4 \\
\hline Chou et al. (2015) & 1 & 1 & 1 & 1 & 1 & 0 & 0 & 0 & 0 & 0 & 5 \\
\hline Crotin et al. (2013) & 1 & 1 & 1 & $\mathrm{U}$ & 1 & 0 & 0 & 0 & 0 & 0 & 4 \\
\hline Crotin et al. (2014) & 0 & 1 & 1 & 1 & 1 & 0 & 0 & 0 & 0 & 0 & 4 \\
\hline Dale et al. (2007) & 0 & 1 & 1 & 0 & 1 & 0 & 0 & 0 & 0 & 0 & 3 \\
\hline Erickson et al. (2016) & 1 & 1 & 1 & 1 & 1 & 0 & 0 & 0 & 0 & 0 & 5 \\
\hline Escamilla et al. (2007) & 1 & 1 & 1 & 0 & 1 & 0 & 0 & 0 & 0 & 0 & 4 \\
\hline Freeston et al. (2014) & 0 & 1 & 1 & $\mathrm{U}$ & 1 & 0 & 0 & 0 & 0 & 0 & 3 \\
\hline Grantham et al. (2014) & 0 & 1 & 0 & 1 & 1 & 0 & 0 & 0 & 0 & 0 & 3 \\
\hline Keeley, Barber \& Oliver (2010) & 0 & 1 & 1 & 1 & 1 & 0 & 0 & 0 & 0 & 0 & 4 \\
\hline Keeley et al. (2017) & 0 & 1 & 1 & 1 & 1 & 0 & 0 & 0 & 0 & 0 & 4 \\
\hline Lyman et al. (2001) & 0 & 1 & 1 & $\mathrm{U}$ & 1 & 1 & 1 & 0 & 0 & 1 & 6 \\
\hline Lyman et al. (2002) & 1 & 1 & 1 & $\mathrm{U}$ & 0 & 1 & 1 & 0 & 0 & 1 & 6 \\
\hline Makhni et al. (2014) & 1 & 1 & 1 & $\mathrm{U}$ & 1 & 1 & 1 & 0 & 0 & 1 & 7 \\
\hline Mullaney et al. (2005) & 0 & 1 & 1 & 0 & 1 & 0 & 0 & 0 & 0 & 0 & 3 \\
\hline Murray et al. (2001) & 0 & 1 & 1 & 1 & 0 & 0 & 0 & 0 & 0 & 0 & 3 \\
\hline Oliver \& Plummer (2010) & 0 & 1 & 1 & 0 & 1 & 0 & 0 & 0 & 0 & 0 & 3 \\
\hline Oliver, Wiemar \& Henning (2016) & 0 & 1 & 1 & $\mathrm{U}$ & 1 & 0 & 0 & 0 & 0 & 0 & 3 \\
\hline Sonne \& Keir (2016) & 1 & 1 & 1 & 0 & 1 & 0 & 0 & 0 & 0 & 0 & 4 \\
\hline Trip, Yochem \& Uhl (2007) & 0 & 1 & 1 & 0 & 1 & 0 & 0 & 0 & 0 & 0 & 3 \\
\hline Wang et al. (2016) & 1 & 1 & 0 & $\mathrm{U}$ & 1 & 0 & 0 & 0 & 0 & 0 & 3 \\
\hline Warren, Szymanski \& Landers (2015) & 0 & 1 & 1 & $\mathrm{U}$ & 1 & 0 & 0 & 0 & 0 & 0 & 3 \\
\hline Whiteside et al. (2016) & 1 & 1 & 1 & 1 & 1 & 0 & 0 & 0 & 0 & 0 & 5 \\
\hline Yang et al. (2014) & 1 & 1 & 1 & 1 & 1 & 1 & 1 & 1 & 0 & 1 & 9 \\
\hline Yang et al. (2016) & 0 & 1 & 1 & 1 & 1 & 0 & 0 & 0 & 0 & 0 & 4 \\
\hline
\end{tabular}


Scoring: "low risk of bias" = 1, "high risk of bias" = 0 , "unable to determine" = U ( scored as 0 ) 
Table 3(on next page)

Kinematic changes with fatigue

A summary of selected pitching kinematic changes following various fatigue protocols. 
1 Table 3. A summary of selected pitching kinematic changes following various fatigue protocols.

\begin{tabular}{|c|c|c|c|c|}
\hline Study & $\begin{array}{c}\text { Sample } \\
\text { Size }\end{array}$ & $\begin{array}{l}\text { Fatigue } \\
\text { Protocol }\end{array}$ & Changes in Kinematics due to Fatigue & Pre-Post Fatigue Change \\
\hline $\begin{array}{l}\text { Escamilla et } \\
\text { al. }(2007)\end{array}$ & $\begin{array}{l}10 \\
\text { collegiate } \\
\text { pitchers }\end{array}$ & $\begin{array}{l}15 \text { pitches per } \\
\text { inning for } 7-9 \\
\text { innings }\end{array}$ & $\begin{array}{l}\text { - Change in trunk flexion during the arm cocking } \\
\text { and acceleration phase (from } 34 \pm 12^{\circ} \text { to } 29 \pm 11^{\circ} \text { ) }\end{array}$ & - $5^{\circ}$ change in trunk flexion \\
\hline $\begin{array}{l}\text { Murray et al. } \\
(2001)\end{array}$ & $\begin{array}{l}7 \text { major } \\
\text { league } \\
\text { pitchers }\end{array}$ & $\begin{array}{l}\text { No protocol, } \\
\text { collection } \\
\text { during games }\end{array}$ & $\begin{array}{l}\text { - Decreased maximum shoulder external rotation } \\
\text { ( } 181^{\circ} \text { in the first inning to } 172^{\circ} \text { in the last) } \\
\text { - Decreased knee angle at ball release }\left(140^{\circ} \text { in first }\right. \\
\text { inning to } 132^{\circ} \text { in the last) }\end{array}$ & $\begin{array}{l}\text { - } 9^{\circ} \text { change in maximum } \\
\text { external rotation } \\
-8^{\circ} \text { change in knee angle }\end{array}$ \\
\hline $\begin{array}{l}\text { Erickson et } \\
\text { al. }(2016)\end{array}$ & $\begin{array}{l}28 \\
\text { adolescent } \\
\text { pitchers }\end{array}$ & $\begin{array}{l}\text { Warmup } \\
\text { followed by } \\
15 \text { pitches per } \\
\text { inning for } 6 \\
\text { innings }\end{array}$ & $\begin{array}{l}\text { - Hip-to-shoulder separation decreased as pitch } \\
\text { count increased (from } 90 \% \pm 40 \% \text { at pitch } 15 \text { to } \\
40 \% \pm 50 \% \text { at pitch } 90 ; p<0.001 \text { ) } \\
\text { - Knee flexion increased with pitch number (from } \\
49 \pm 15^{\circ} \text { to } 53 \pm 15^{\circ}, p=0.008 \text { ) } \\
\text { - Increased shoulder external rotation and total } \\
\text { range of motion post pitching } \\
\text { - Lower half muscles fatigued before changes in } \\
\text { upper extremity kinematics occurred }\end{array}$ & $\begin{array}{l}\text { - } 50 \% \text { change in hip-to- } \\
\text { shoulder separation } \\
\text { - } 4^{\circ} \text { change in knee flexion }\end{array}$ \\
\hline $\begin{array}{l}\text { Mullaney et } \\
\text { al. (2005) }\end{array}$ & $\begin{array}{l}13 \\
\text { university } \\
\text { pitchers }\end{array}$ & $\begin{array}{l}99 \text { pitches } \\
\text { over } 7 \text { innings }\end{array}$ & $\begin{array}{l}\text { - Postgame results showed selective fatigue of } 15 \% \\
\text { in shoulder flexion }(p=0.02) ; 18 \% \text { in shoulder } \\
\text { internal rotation }(p=0.03) ; \text { and } 11 \% \text { in shoulder } \\
\text { adduction }(p=0.01)\end{array}$ & $-\mathrm{N} / \mathrm{A}$ \\
\hline
\end{tabular}




\begin{tabular}{|c|c|c|c|c|}
\hline $\begin{array}{l}\text { Keeley et al } \\
(2010)\end{array}$ & $\begin{array}{l}10 \\
\text { collegiate } \\
\text { pitchers }\end{array}$ & $\begin{array}{l}\text { Five pitches } \\
\text { for strikes } \\
\text { followed by } 2 \\
\mathrm{~kg} \text { ball throws } \\
\text { until } \\
\text { maximum } \\
\text { perceived } \\
\text { fatigue }\end{array}$ & $\begin{array}{l}\text { - Changes in lateral pelvis tilt at maximum external } \\
\text { rotation (from }-10.8 \pm 11.8^{\circ} \text { to }-14.8 \pm 11.3^{\circ} \text { ) and } \\
\text { ball release (from }-3.36 \pm 5.24^{\circ} \text { to }-6.82 \pm 3.87^{\circ} \text { ) } \\
\text { between non-fatigued and fatigued conditions ( } \mathrm{p}< \\
\text { 0.05) (negative represents tilt to left) }\end{array}$ & $\begin{array}{l}-4^{\circ} \text { change in lateral pelvis } \\
\text { tilt at maximum external } \\
\text { rotation } \\
-3.5^{\circ} \text { change in lateral } \\
\text { pelvis tilt at ball release }\end{array}$ \\
\hline $\begin{array}{l}\text { Chou et al. } \\
(2015)\end{array}$ & $\begin{array}{l}16 \text { high } \\
\text { school } \\
\text { pitchers }\end{array}$ & $\begin{array}{l}10 \text { maximum } \\
\text { effort fastball } \\
\text { warmups, } \\
100 \text { pitches, } \\
10 \text { pitches } \\
\text { post throwing } \\
\text { session }\end{array}$ & $\begin{array}{l}\text { - Increased knee flexion (from } 53.6 \pm 21.5^{\circ} \text { to } 56.1 \\
\pm 22.2^{\circ} ; \mathrm{p}=0.01 \text { ) and trunk flexion (from } 21.4^{\circ} \pm \\
5.4^{\circ} \text { to } 24.2^{\circ} \pm 6.6^{\circ} ; \mathrm{p}=0.01 \text { ) at instant of ball } \\
\text { release } \\
\text { - Shoulder horizontal abduction decreased at the } \\
\text { instant of front foot strike (from } 21.1 \pm 11.0^{\circ} \text { to } \\
18.7 \pm 10.1^{\circ} ; \mathrm{p}=0.01 \text { ) } \\
\text { - } \text { Maximum forearm pronation decreased during the } \\
\text { acceleration phase (from } 27.4 \pm 12.3 \text { to } 22.4 \pm \\
10.6^{\circ} ; \mathrm{p}=0.01 \text { ) } \\
\text { - } \text { Elbow valgus }\left(8.8 \pm 3.3^{\circ} \text { to } 6.9 \pm 3.9^{\circ} ; \mathrm{P}=0.01 \text { ) }\right. \\
\text { and forearm pronation }\left(24.9 \pm 11.2^{\circ} \text { to } 20.1 \pm 8.9^{\circ} ;\right. \\
\mathrm{p}=0.01 \text { ) decreased at ball release as fatigue } \\
\text { accumulated }\end{array}$ & $\begin{array}{l}\text { - } 2.5^{\circ} \text { change in knee } \\
\text { flexion at ball release } \\
-2.8^{\circ} \text { change in trunk } \\
\text { flexion at ball release } \\
-2.4^{\circ} \text { change in horizontal } \\
\text { abduction at front foot } \\
\text { strike } \\
\text { - } 5^{\circ} \text { change in forearm } \\
\text { pronation during } \\
\text { acceleration } \\
-1.9^{\circ} \text { change in elbow } \\
\text { valgus angle at ball } \\
\text { release } \\
-4.8^{\circ} \text { change in forearm } \\
\text { pronation at ball release }\end{array}$ \\
\hline $\begin{array}{l}\text { Oliver \& } \\
\text { Plummer } \\
(2010)\end{array}$ & $\begin{array}{l}14 \text { high } \\
\text { school } \\
\text { pitchers }\end{array}$ & $\begin{array}{l}\text { Five pitches } \\
\text { for strikes } \\
\text { followed by } 2 \\
\mathrm{~kg} \text { ball throws } \\
\text { until } \\
\text { maximum }\end{array}$ & $\begin{array}{l}\text { - Kinematic data was collected, but results were not } \\
\text { shown within the study's results }\end{array}$ & $-\mathrm{N} / \mathrm{A}$ \\
\hline
\end{tabular}




\begin{tabular}{|c|c|c|c|c|}
\hline & & $\begin{array}{l}\text { perceived } \\
\text { fatigue }\end{array}$ & & \\
\hline $\begin{array}{l}\text { Oliver, } \\
\text { Weimar \& } \\
\text { Henning } \\
(2016)\end{array}$ & $\begin{array}{l}23 \text { youth } \\
\text { pitchers }\end{array}$ & 75 pitch limit & $\begin{array}{l}\text { - Kinematic data was collected, but results were not } \\
\text { shown within the study's results }\end{array}$ & $-\mathrm{N} / \mathrm{A}$ \\
\hline $\begin{array}{l}\text { Tripp et al. } \\
(2007)\end{array}$ & $\begin{array}{l}16 \\
\text { collegiate } \\
\text { pitchers }\end{array}$ & $\begin{array}{l}\text { 3-5 warmup } \\
\text { pitches, } \\
\text { throwing } \\
\text { every } 5 \\
\text { seconds until } \\
\text { maximum } \\
\text { perceived } \\
\text { fatigue }\end{array}$ & $\begin{array}{l}\text { - Arm cocked position changed from } 12.4 \mathrm{~mm} \text { pre- } \\
\text { fatigue to } 24.1 \mathrm{~mm} \text { post-fatigue (decreased acuity) } \\
\text { - Ball release position changed from } 20.8 \mathrm{~mm} \text { pre- } \\
\text { fatigue to } 41.7 \mathrm{~mm} \text { post-fatigue (decreased acuity) }\end{array}$ & $\begin{array}{l}\text { - } 11.7 \mathrm{~mm} \text { change in joint } \\
\text { position sense in arm } \\
\text { cocked position } \\
\text { - } 20.9 \mathrm{~mm} \text { change in joint } \\
\text { position sense at ball } \\
\text { release }\end{array}$ \\
\hline $\begin{array}{l}\text { Grantham et } \\
\text { al. (2014) }\end{array}$ & $\begin{array}{l}11 \\
\text { collegiate } \\
\text { pitchers }\end{array}$ & $\begin{array}{l}\text { No protocol, } \\
\text { collection } \\
\text { during games }\end{array}$ & $\begin{array}{l}\text { - Increased hip flexion at hand separation }(p= \\
0.022) \\
\text { - Increased hip flexion }(p=0.002) \text { and shoulder } \\
\text { lateral tilt }(p=0.048) \text { at maximum external } \\
\text { rotation was observed in innings in which the } \\
\text { pitcher threw over } 15 \text { pitches }\end{array}$ & $-\mathrm{N} / \mathrm{A}$ \\
\hline
\end{tabular}




\section{Table 4(on next page)}

Performance changes with fatigue

Studies examining velocity prior to, and post-fatigue protocol. Absolute velocity, pre and post fatigue, as well as the relative change in velocity. Additionally, studies related to throwing accuracy listed. 
Table 4: Studies examining velocity prior to, and post-fatigue protocol. Absolute velocity, pre and post fatigue, as well as the relative change in velocity. Additionally, studies related to throwing accuracy listed.

\begin{tabular}{|c|c|c|c|c|c|c|}
\hline Study & Sample Size & Fatigue Protocol & $\begin{array}{l}\text { Velocity Pre- } \\
\text { Fatigue }\end{array}$ & $\begin{array}{l}\text { Velocity Post- } \\
\text { Fatigue }\end{array}$ & $\begin{array}{l}\text { Relative Change } \\
\text { (\% velocity } \\
\text { decrease from } \\
\text { pre-fatigue) }\end{array}$ & Throwing Accuracy/Other \\
\hline $\begin{array}{l}\text { Dale et al. } \\
\quad(2007)\end{array}$ & $\begin{array}{c}10 \text { collegiate } \\
\text { pitchers }\end{array}$ & $\begin{array}{c}60 \text { maximum effort } \\
\text { pitches, } 15 \text { each inning }\end{array}$ & $82.5 \pm 1.3 \mathrm{mph}$ & $81.5 \pm 0.9 \mathrm{mph}$ & $-1.2 \%$ & N/A \\
\hline $\begin{array}{l}\text { Crotin et al. } \\
\qquad(2014)\end{array}$ & $\begin{array}{c}19 \\
\text { collegiate/high } \\
\text { school pitchers }\end{array}$ & $\begin{array}{c}\text { Warmup. } \\
80 \text { pitches ( } 15 \text { seconds } \\
\text { between pitches, } 9 \\
\text { minutes between innings) }\end{array}$ & $\begin{array}{l}\text { Over-stride: } \\
81.6 \pm 5.4 \mathrm{mph} \\
\text { Under-stride: } \\
80.3 \pm 5.0 \mathrm{mph}\end{array}$ & $\begin{array}{l}\text { Over-stride: } \\
79.8 \pm 5.4 \mathrm{mph} \\
\text { Under-stride: } \\
79.8 \pm 5.0 \mathrm{mph}\end{array}$ & $\begin{array}{c}\text { Over-stride: } \\
\quad-2.2 \% \\
\text { Under-stride: } \\
\quad-0.6 \%\end{array}$ & $\mathrm{~N} / \mathrm{A}$ \\
\hline $\begin{array}{l}\text { Keeley et al. } \\
\quad(2010)\end{array}$ & $\begin{array}{c}10 \text { collegiate } \\
\text { pitchers }\end{array}$ & $\begin{array}{l}\text { Five pitches for strikes. } \\
2 \mathrm{~kg} \text { ball throws until } \\
\text { maximum perceived } \\
\text { fatigue }\end{array}$ & $75.0 \mathrm{mph}$ & $72.0 \mathrm{mph}$ & $-4.0 \%$ & N/A \\
\hline $\begin{array}{l}\text { Murray et al. } \\
\text { (2001) }\end{array}$ & $\begin{array}{c}7 \text { major league } \\
\text { pitchers }\end{array}$ & $\begin{array}{l}\text { No protocol, collection } \\
\text { during season }\end{array}$ & $90.0 \mathrm{mph}$ & $85.0 \mathrm{mph}$ & $-5.6 \%$ & N/A \\
\hline $\begin{array}{l}\text { Erickson et al. } \\
\qquad(2016)\end{array}$ & 28 male pitchers & $\begin{array}{l}\text { Warmup. } 15 \text { pitches per } \\
\text { inning for } 6 \text { innings }\end{array}$ & $73.0 \pm 5.0 \mathrm{mph}$ & $71.0 \pm 6.0 \mathrm{mph}$ & $-2.7 \%$ & N/A \\
\hline Escamilla et al. & 10 collegiate & 15 pitches per inning for & $77.6 \pm 4.0 \mathrm{mph}$ & $75.4 \pm 3.4 \mathrm{mph}$ & $-2.8 \%$ & N/A \\
\hline
\end{tabular}




\begin{tabular}{|c|c|c|c|c|c|c|}
\hline (2007) & pitchers & 7-9 innings & & & & \\
\hline $\begin{array}{l}\text { Whiteside et } \\
\text { al. (2016) }\end{array}$ & $\begin{array}{l}129 \text { MLB } \\
\text { pitchers }\end{array}$ & $\begin{array}{l}\text { No protocol, collection } \\
\text { during season }\end{array}$ & N/A & N/A & N/A & $\begin{array}{l}\text { Percentage of hard-thrown } \\
\text { pitches decreased as game } \\
\text { progressed. Largest decrease } \\
\text { in ball speed between } 1^{\text {st }} \text { and } \\
7^{\text {th }} \text { inning (velocity not } \\
\text { provided) }\end{array}$ \\
\hline $\begin{array}{l}\text { Wang et al. } \\
\quad(2016)\end{array}$ & 15 pitchers & $\begin{array}{c}\text { Six maximum effort } \\
\text { fastballs before fatigue } \\
\text { protocol. } \\
\text { 8-12 reps, } 3 \text { sets, wrist } \\
\text { ulnar deviation and } \\
\text { flexion with dumbbell. } \\
\text { Within } 1 \text { minute of } \\
\text { completion, pitcher threw } \\
6 \text { maximum effort } \\
\text { fastballs }\end{array}$ & N/A & N/A & N/A & $\begin{array}{c}\text { Strike percentage changed } \\
\text { from } 70.1 \pm 17.8 \% \text { pre- } \\
\text { fatigue to } 49.3 \pm 17.2 \% \text { post- } \\
\text { fatigue }\end{array}$ \\
\hline $\begin{array}{l}\text { Crotin et al. } \\
\quad(2013)\end{array}$ & $\begin{array}{l}12 \text { minor league } \\
\text { pitchers }\end{array}$ & $\begin{array}{l}\text { No protocol, collection } \\
\text { during season }\end{array}$ & N/A & N/A & N/A & $\begin{array}{c}\text { Home run rate increased with } \\
\text { each pitch }\end{array}$ \\
\hline $\begin{array}{l}\text { Bradbury \& } \\
\text { Forman (2012) }\end{array}$ & $\begin{array}{l}\text { 1,058 MLB } \\
\text { pitchers }\end{array}$ & $\begin{array}{l}\text { No protocol, collection } \\
\text { during seasons }\end{array}$ & N/A & N/A & N/A & $\begin{array}{l}\text { With each pitch in preceding } \\
\text { game, } 5^{\text {th }} \text { game and } 10^{\text {th }} \\
\text { game, the pitcher's Earned } \\
\text { Run Average increased by } \\
0.007,0.014 \text {, and } 0.022 \\
\text { respectively }\end{array}$ \\
\hline
\end{tabular}




\begin{tabular}{|c|c|c|c|c|c|c|}
\hline $\begin{array}{l}\text { Yang et al. } \\
\text { (2016) }\end{array}$ & $\begin{array}{c}7 \text { intercollegiate } \\
\text { pitchers }\end{array}$ & $\begin{array}{c}15 \text { pitches per inning for } \\
7 \text { innings }\end{array}$ & N/A & N/A & N/A & $\begin{array}{l}\text { Both throwing accuracy and } \\
\text { velocity significantly } \\
\text { decreased below baseline } \\
\text { following the } 4^{\text {th }} \text { inning in the } \\
\text { 8-second }(p=0.05) \text { and } 12- \\
\text { second }(p=0.05) \text { trials }\end{array}$ \\
\hline $\begin{array}{l}\text { Keeley et al. } \\
\qquad(2014)\end{array}$ & $\begin{array}{l}14 \text { youth } \\
\text { pitchers }\end{array}$ & 88 pitch simulated game & N/A & $\mathrm{N} / \mathrm{A}$ & N/A & $\begin{array}{l}\text { Total and first pitch strike } \\
\text { percentage decreased at } \\
\text { "moderate" perceived fatigue } \\
\text { levels }(52.4 \% \text { and } 49.8 \%) \text { and } \\
\text { further at "severely" fatigued } \\
(45.3 \% \text { and } 40.0 \%)\end{array}$ \\
\hline
\end{tabular}


Table 5 (on next page)

Injury and fatigue

A summary of findings related to pain and injury resulting from pitching. 
1 Table 5. A summary of findings related to pain and injury resulting from pitching

\begin{tabular}{|c|c|c|c|c|}
\hline Study & Sample Size & Fatigue Protocol & $\begin{array}{l}\text { Data Collection } \\
\text { Process }\end{array}$ & Findings \\
\hline $\begin{array}{l}\text { Lyman et } \\
\text { al. }(2001)\end{array}$ & $\begin{array}{l}298 \text { youth } \\
\text { pitchers (aged } \\
9-12 \text { years) }\end{array}$ & $\begin{array}{l}\text { No protocol, } \\
\text { collection during } \\
\text { season }\end{array}$ & $\begin{array}{l}\text { Conducted over the } \\
\text { span of two seasons, } \\
\text { pitchers were } \\
\text { interviewed via } \\
\text { telephone after each } \\
\text { game pitched }\end{array}$ & $\begin{array}{l}\text { - Elbow pain was reported in } 26 \% \text { of pitchers, while shoulder pain } \\
\text { was reported in } 32 \% \text { of pitchers } \\
\text { - Risk factors associated with elbow and shoulder pain included } \\
\text { decreased self-satisfaction, increased pitch count, and in-game } \\
\text { arm fatigue } \\
\text { - Increased age, weight, and lifting weights during the season } \\
\text { linked to increased elbow pain }\end{array}$ \\
\hline $\begin{array}{l}\text { Lyman et } \\
\text { al. (2002) }\end{array}$ & $\begin{array}{l}476 \text { youth } \\
\text { pitchers (aged } \\
9-14 \text { years) }\end{array}$ & $\begin{array}{l}\text { No protocol, } \\
\text { collection during } \\
\text { season }\end{array}$ & $\begin{array}{l}\text { Questionnaires were } \\
\text { assigned to pitchers } \\
\text { before and after the } \\
\text { season. Interviews } \\
\text { were conducted during } \\
\text { the season after each } \\
\text { game }\end{array}$ & $\begin{array}{l}\text { - Curveballs were associated with a } 52 \% \text { increased risk of } \\
\text { shoulder pain, while the slider was associated with an } 86 \% \\
\text { increased risk of elbow pain } \\
\text { - } 28 \% \text { of pitchers reported elbow pain and } 35 \% \text { of pitchers } \\
\text { reported shoulder pain at least once during the season } \\
\text { - Elbow and shoulder pain increased significantly with pitch count }\end{array}$ \\
\hline $\begin{array}{l}\text { Freeston } \\
\text { et al. } \\
(2014)\end{array}$ & $\begin{array}{c}13 \text { elite } \\
\text { pitchers (aged } \\
19.6 \pm 2.6 \\
\text { years) }\end{array}$ & $\begin{array}{l}2 \text { test days } \\
\text { (minimum of } 7 \\
\text { days apart), } \\
5-10 \text { minutes of } \\
\text { moderate intensity } \\
\text { running, 5-10 } \\
\text { minutes of } \\
\text { stretching, 10-15 } \\
\text { minutes of } \\
\text { throwing, } \\
\text { throwing or } \\
\text { running program }\end{array}$ & $\begin{array}{l}\text { A throwing protocol } \\
\text { was assigned to } \\
\text { subjects on the first } \\
\text { day, a running protocol } \\
\text { was assigned on the } \\
\text { second day }\end{array}$ & $\begin{array}{l}\text { - Significant increase in velocity following the throwing program } \\
(3.5 \pm 0.7 \mathrm{~km} / \mathrm{h} \text { vs. } 1.4 \pm 0.5 \mathrm{~km} / \mathrm{h} \text {, respectively; } \mathrm{p} \leq 0.05) \\
\text { - Throwing velocity, a sign of general fatigue, whereas throwing } \\
\text { accuracy and arm soreness are indicators of arm fatigue }\end{array}$ \\
\hline $\begin{array}{l}\text { Yang et al. } \\
\text { (2014) }\end{array}$ & $\begin{array}{l}754 \text { youth } \\
\text { pitchers (aged } \\
9-18 \text { years) }\end{array}$ & $\begin{array}{l}\text { No protocol, } \\
\text { collection during } \\
\text { season }\end{array}$ & $\begin{array}{l}\text { A national survey was } \\
\text { conducted }\end{array}$ & $\begin{array}{l}\text { - } 69.2 \% \text { of pitchers reported pitching through arm tiredness } \\
\text { multiple times throughout the season } \\
\text { - } 37.9 \% \text { of pitchers reported multiple incidences of arm pain }\end{array}$ \\
\hline
\end{tabular}




\begin{tabular}{|c|c|c|c|c|}
\hline & & & & throughout the season \\
\hline $\begin{array}{l}\text { Makhni et } \\
\text { al. (2014) }\end{array}$ & $\begin{array}{l}203 \text { youth } \\
\text { pitchers (aged } \\
8-18 \text { years) }\end{array}$ & $\begin{array}{l}\text { No protocol, } \\
\text { collection during } \\
\text { season }\end{array}$ & $\begin{array}{l}\text { Epidemiological study. } \\
\text { Survey. }\end{array}$ & $\begin{array}{l}\text { - } 23 \% \text { of pitchers reported prior overuse injury } \\
\text { - } 30 \% \text { of players reported arm pain at decreased level of } \\
\text { satisfaction } \\
\text { - } 46 \% \text { of players were told on at least one occasion to pitch } \\
\text { through arm pain }\end{array}$ \\
\hline $\begin{array}{l}\text { Sonne \& } \\
\text { Keir } \\
(2016) \\
\end{array}$ & 73 pitchers & $\begin{array}{l}\text { No protocol, } \\
\text { collection during } \\
\text { season }\end{array}$ & $\begin{array}{l}\text { Retrospective Study. } \\
\text { Pitching data retrieved } \\
\text { from a public database. }\end{array}$ & $\begin{array}{l}\text { - Reduced effectiveness of the flexor-pronator mass reduces joint } \\
\text { rotational stiffness, which in turn increases the strain on the UCL } \\
\text { during pitching, therefore increasing risk of injury }\end{array}$ \\
\hline $\begin{array}{l}\text { Warren, } \\
\text { Szymanski } \\
\text { \& Landers } \\
\quad(2015)\end{array}$ & $\begin{array}{l}21 \text { collegiate } \\
\text { pitchers (aged } \\
20.4 \pm 1.4 \\
\text { years) }\end{array}$ & $\begin{array}{l}3 \text { simulated, } 5- \\
\text { inning games } \\
\text { (Max } 70 \text { pitches } \\
\text { per game) }\end{array}$ & $\begin{array}{l}\text { Evaluated the effects } \\
\text { of 3recovery protocols } \\
\text { on range of motion, } \\
\text { heart rate, rating of } \\
\text { perceived exertion, } \\
\text { and blood lactate }\end{array}$ & $\begin{array}{l}\text { - Study looked into injuries in pitching, but did not comment on } \\
\text { any related findings }\end{array}$ \\
\hline
\end{tabular}

